\title{
Mentoring, Institutional Barriers, Structures of Justice: A Dialogue Across Positions of Privilege and Power
}

\author{
Matthew Ovalle and Andrew Dell'Antonio
}

\section{[content warning: mental illness and ableism, suicide]}

Note: Matthew and I decided to publish our contribution essentially as it was delivered because I wanted to maintain the centering of his voice, experience, and insights that we had established in San Antonio. It's worth mentioning, however, that, in addition to understanding the need for educational accommodation through my disabled children, my own anxiety and ADHD (the latter identified recently) have made me aware of my own neurodivergence and my strategies for self-accommodation, to which I have had access because of my privileged identities. This reinforces my commitment to principles of Universal Design for Learning and other collaborative and kindness-informed pedagogies to push against the structural ableism of the neoliberal academy. ${ }^{1}$

\section{Andrew}

I'd like to start with the thought that we've been having that white supremacy isn't just tiki torches. It's also the foundation on which the entire academy in the US is built. And so it can be painful - no tears here, but painful for those of us who have gained power and authority in what we were indoctrinated to believe was a meritocracy, only to realize that our ostensible merit springs just from privilege. And so it's really, I think, only in conversation with those who weren't born to that kind of privilege - weren't raised in that kind of privilege - that we can rethink the structures that create the barriers to equity. And maybe we should reframe inclusion as partnership, sharing of authority, being willing to question and relinquish assumptions, and moving to gatekeeping practices that are accountable to wider communities.

And the main point I want to make here is that - we talk a lot about accommodations. We'll talk today a bit about what kind of accommodations we make for people who, for whatever reason, don't appear to be succeeding within the current academic framework. We need to change the design of what we do. We don't need to benevolently dispense opportunities; we need to share them out. And if we are privileged to be in the system, we have the authority to disrupt it. So, whether or not we can fully change the system, we really do need to create Current Musicology 107 (Fall 2020)

(92020 Dell'Antonio and Ovalle. This is an open access article distributed under the terms of the Creative CommonsAttribution-NonCommercial-NoDerivatives License (CC BY-NC-ND). 


\section{Project Spectrum Colloquy}

pathways to equity, by dismantling the barriers of habit that make us think that there's a single way to create admission into programs, to create opportunity to study. So, I'm going to pass it for now to Matt, so he can bring his experiences to bear. I will chime in, perhaps, but he has a lot more important things to say about this than I do.

\section{Matthew}

Thank you. I can really only speak to my experience. I did my undergraduate and graduate work at the University of Texas. I decided to stay at UT for my $\mathrm{PhD}$, even though I had looked at other programs, because I was lucky enough to feel supported by my faculty-support that I felt I maybe wouldn't have received at another university. The first thing I want to say is that I do not belong in academia. I am a queer, trans, disabled man of color. Spanish is my first language. I have seven tattoos, my nose is pierced, and I like to use the word "fuck." Academia was a very alienating place for me.

Part of it is because I am not from Texas. I was born in Miami, Florida and I am a proud Dominican man. As I mentioned, Spanish is my first language. When I moved to Texas, I definitely had culture shock. I had never been in a space surrounded by so many White people, to be frank, and I had definitely never been in a space where I felt that I couldn't catch up. And I didn't know anything. My very first semester of undergrad, I took a required piano class. Around Christmas time we started playing more "traditional" Christmas music. We played "The First Noël," and I had never heard that song before, ever. A lot of my friends were shocked that I had never heard it, to which I responded "Yeah, but you have you heard 'El burrito sabanero'?" That's what we sing where I come from.

The truth of the matter is that, as I mentioned, I am not the kind of person that belongs in academia. The reason that I am in academia is because of the man in conversation with me. Because when I was an undergrad, I started to exhibit symptoms of what I know now was bipolar disorder. I had a complete mental breakdown, and had it not been for Dr. Dell'Antonio, and his encouragement for me to receive accommodations, because luckily the University of Texas does have a Services for Students with Disabilities office, I would have dropped out of college. I would not have made it-I certainly would not have made it to graduate school or to a $\mathrm{PhD}$ program. I am very well aware of the fact that these programs and offices do not exist at every university. I am also very well aware of the fact that I have a fear of going into the work-force because I have these 


\section{Current Musicology}

accommodations as a student, but there is no guarantee that I will have them as a member of a faculty, at a university in any department. So what do I do? I don't know.

One of the things that we often talk about is how we can teach our classes in a way that is accommodating and accessible. I had a conversation with a student just yesterday who, by most traditional standards, is doing poorly in my class, in that her exam grades are very, very low. And one of the things that I said to her was that I hate exams. How am I supposed to take 60 students with 60 different ways of learning, make one exam, and expect them all to pass? It's impossible. Not all students are able to take exams in general. It is not a universal method of assessment. I have certain students who come into my office every week. We have very nuanced conversations which indicates that they understand the music and the material perfectly, but when they take the exams, they fail. And it's not their fault, it's the way that the university is built.

I have to give exams and I have to have students write papers, but if I could design a course outside of these bounds, I wouldn't have my students do either. Most semesters (if not every single semester) that I have taught, I have had international students. English is not their first language and they are struggling because they are just now having to learn to both speak the language and write it at the academic level for the first time. How do I get them to write an essay when they don't have the same resources as their classmates for whom English is their first language? How do I grade that? Where do I base my grammar? Even in my own work, something that I was talking about recently is that I constantly question my use of grammar in my papers, because I was taught and raised in a Spanish-speaking household. I don't remember all of the grammatical rules of English, because, frankly, there are too many of them. And they're ridiculous. I think we can all agree with that. But one of the things that we've talked about is trying to create an alternative pathway to learning.

I think that everybody here can agree that when we teach a class, we have a goal in mind. As educators, we have an idea of what we want our students to be able to do at the end of the class. I recently got to a point where I am teaching a class at the University of Texas. I am not just a TA anymore. And I decided that my goal was for students who are non-majors to be able to listen to music and take something away from it that they maybe would not have noticed before. A test doesn't necessarily tell me if they can do that or not. How do I create a system that allows a student who has problems taking tests, a student who has problems attending classes, a student who needs extended deadlines, to get to the same 


\section{Project Spectrum Colloquy}

end-goal, the same finish line at the same time? That is something I think about a lot; we have 15 weeks, and not everybody can learn that way.

The only reason I am sitting here is because Dr. Dell'Antonio created an alternate pathway for me. Because when I had a mental breakdown, I was taking his first semester music history class, I went to his office and I sobbed. I didn't mean to. I didn't know it was going to happen, but it was one of the most important moments of my life. Dr. Dell'Antonio looked at me and said: "my daughter is disabled, I understand what this is like, and I'm going to help you." I had never heard that before. Ever. He essentially allowed me to not go to class if I didn't need to, if I could not make it, and to do my work in my own time. So instead, I would make my own notes, I would look through the material myself, and I would meet with my TA, Dr. Heather Buffington-Anderson. Dr. Buffington-Anderson was also committed to my success in the course and would review the material with me week by week. And I passed the class because I had an alternative pathway.

How do we create that for other students? How do we accommodate all students? What does it look like to even get accommodations? Because that is something that is also very difficult. I have had accommodations since 2011. Just recently, I realized that I needed new accommodations because I've had new issues arise-or at least they seem to be issues in a University setting. I needed to revise my accommodations. Well, guess what? They said I needed to be reevaluated. Who has the money to see a therapist? Not everybody. Who has the ability to self-advocate? Who has the understanding of themselves to know that they are dealing with mental illness, to get help, to get to a point where they realize that we do have systems in place that might help them? But students don't always feel comfortable reaching out for help. What do we do? I needed to be reevaluated-and I need to say, because I was very upset about this-I had to pay $\$ 50$ for my therapist to fill out four pieces of paper, and it was mostly just checking boxes. I then had to make time in my very limited schedule to go and meet with my counselor and discuss my new accommodations.

And that is not something that all of my students can do. I had a student who trusted me enough to come out to me. He told me that he was gay and he was having trouble. This is why he wasn't coming to class. He was still in the closet and his family had just found out that his cousin was gay had a very negative reaction. And that obviously affected him. He broke down and cried in my office. And one of the very difficult things that I had to do was to try and refer him to our resources knowing that certain resources on campus just don't work. We have a counseling and mental health center; it is severely understaffed. We 


\section{Current Musicology}

have 50,000 students on the University of Texas campus, and we only have about 30 therapists. Not only that, but like, you can only see one (and that's if you can even get in to see one). Even if you do get in, they can only meet with you once every three weeks-once every three weeks, OK? That is unacceptable. Every student should be able-every person should be able to have access to the care that they need. And we know that this is not a possibility.

So, the question that we keep coming back to is: how do we help these students? How do we help students who need accommodations, and don't have an official letter from the Services for Students with Disabilities office? Do we help? Yes. The answer is yes. I have always been more than willing to help because I received help myself and I would not be here without it. And I'm going to be frank and put out a content warning and then sort of wrap up because I know I'm going off on a tangent here.

So, as I mentioned, I'm issuing a content warning. Right before I met with Dr. Dell'Antonio, I attempted suicide. And I'm thankful every single day that I failed. But I was at that level in my life. I was in that much pain. But I still had to get to a point where $I$ had to send an email, where $I$ had to set up a meeting, and where $I$ had to feel comfortable enough to talk about what was happening with me. And this is not always possible. So when I see a student who is not always coming to class, I don't automatically believe that it's because they won't - it's because they can't. We have to try and be more compassionate, I think, to all students and not assume that they are just sort of blowing our classes off, even if it's kind of hurting our egos a little bit. You work so hard, and you put so much work into a class. But I really think that alternative pathways are the way to go. And they're not always easy to spot. But the work that we would have to do on the other side to create them is worth it, I think.

\footnotetext{
Notes

${ }^{1}$ For more theoretical and practical detail see my "Cripping the Music History Classroom: Disability, Accommodation, Universal Design for Learning," in Norton Guide to Teaching Music History, edited by C. Matthew Balensuela (New York: W. W. Norton, 2019), 247-260; Jay Dolmage’s “Universal Design: Places to Start,” Disability Studies Quarterly 35 (2015), https://dsq-sds.org/article/view/4632/3946; and Jay Dolmage, Academic Ableism: Disability and Higher Education (Ann Arbor, MI: University of Michigan Press, 2017).
} 